\title{
Accounting Firms Transformation and Investor Protection
}

\author{
Wenhao Tan ${ }^{1, ~ a}$, Zhenpeng $\mathrm{Ma}^{2, \mathrm{~b}, *}$ \\ ${ }^{1}$ School of Accounting, Nanjing University of Finance and Economics, Nanjing, Jiangsu Province, P. R. \\ China \\ ${ }^{2}$ School of Medical Management, Taishan Medical University, Taian, Shandong Province, P. R. China \\ ae-mail: twhanenao@163.com;'be-mail: mazhen7@126.com
}

Keywords: Special general partnership; Legal responsibility; Investor protection

\begin{abstract}
The outburst of financial crisis gives a big hit to the global capital market, and makes the investors had a new cognition about the CPA(Certified Public Accountants). The capital market cannot develop healthily without the certified public accountants. The article aims to explain the legal responsibility of special general partnership, to expound the operation mechanism and responsibility formation mechanism of general partnership. It also aims to make a further analysis on problems of legal responsibility in special general partnership, in order to put forward how to define error or fraud, to set up the responsibility evaluation standard and restriction mechanism. The final purpose is to create a good guarantee system for the investors and promote the healthy development of capital market.
\end{abstract}

\section{Introduction}

Interim provisions on Promoting the Large and Medium-sized Accounting Firms to Adopt the Special General Partnership (Draft), which was published by the Ministry of Finance in January 2010 turned a new page for Chinese CPA and greatly encouraged the working enthusiasm of certified public accountants and gave greater initiative to the certified public accountants [1] .However, a hard problem followed, which is how to define the legal responsibility of CPA. That problem will directly relate to the investors' lawful rights and interests and influence the development of CPA, especially the development of special general partnership.

\section{The legal responsibility of CPA}

The legal duty of CPA is collecting sufficient audit evidence, delivering appropriate suggestion on authenticity of finance reports during the process of auditing. The inevitable risks greatly influenced the CPA's auditing working because of the information asymmetry between CPA and the auditee. Although the CPA has followed the requirement of auditing independently, the CPA is likely to face the risk of auditing failure which will result in legal responsibility. We can divide the legal responsibility into three kinds according to the consequence degree.

\subsection{Ordinary fault responsibility}

The cause of this kind of responsibility lies in that the CPA does not strictly follow the rule of auditing independently. The CPA followed the rule of auditing independently to some degree, but not strictly. It may due to carelessness or lacking of standardization and ability. The CPA should undertake lighter legal responsibility since they are guiltless subjectively.

\subsection{Serious fault responsibility}

Serious fault responsibility refers that CPA does not follow the rule of auditing independently at all which results in great loss for the investors. That kind of responsibility is against to professional standard and a kind of dereliction of duty which should be punished severely. 


\subsection{Fraud responsibility}

The CPA just does not have a serious attitude towards the job, not by purpose in the above responsibilities. However, the fraud responsibility is another case. It is a kind of responsibility which is motivated by subjectively cheating the investors and providing false guarantee and bringing economic losses to the investors. That legal responsibility, which greatly damages the rights and interests of investors and related stakeholders, should be punished in order to maintain the healthy development of CPA.

\section{The operation mechanism of special general partnership}

\subsection{The definition of special general partnership}

General partnership is defined as a combo in which every partner share risks and interests together. That partnership has effectively protected the partners' rights and interests during a long period. However, to a certain extent, it restrains partners' initiative and creativity and obstructs accounting firm's fast development. Another operation model named special general partnership was put forward to surmount the bottleneck. Special general partnership is defined that the accounting firm does not undertake the responsibility whenever the partners make light or serious faults. Relevant partners undertake unlimited responsibility, while irrelevant partners undertake limited responsibility [2] 'That operation model effectively protects the irrelevant partners' interests and urges each partner to strictly follow the rule of auditing independently, to avoid unnecessary legal responsibility.

\subsection{The operation aim of special general partnership}

Special general partnership aims to protect the lawful rights of irrelevant partners and restrict the profession behavior of executive partners. It also requires every partner to strictly follow the profession rules, to firmly set up risk awareness, to strengthen responsibility restraint mechanism, to perfect accountability mechanism.

\subsection{CPA's legal responsibility based on investor protection}

It is scientific and reasonable for rational investors to make an investment decision by analyzing the finance reports. Investment losses which caused by false financial information require the CPA and the auditee to undertake civil liability.

\subsection{The prisoner's dilemma of demarcating CPA's legal responsibility}

Demarcating CPA's legal responsibility is the game of balancing interest groups. If the auditee undertakes the majority of legal responsibility, the investors feel it exciting. However, it is a imagined case because of the operability of compensation and the definition of loss. Even it is true case it cannot keep balance because the game players are the auditee and the accounting firm. If the auditee compromises, the accounting firm will always provide false information which will damages more and more investors' interest and break that balance. On the contrary, certified public accountants undertake most responsibilities. It will also break the balance. Moreover, there are several pieces of confusion as follows: (1) It is necessary to clearly ascertain who the undertaker of ultimate responsibility is in order to protect the investors' lawful rights and interests. (2) In general, ordinary fault, serious fault and fraud responsibility constitute CPA's legal responsibility. (3) Rights and inability are the two aspects of contradictory unity. The CPA define own responsibility by whether strictly follow profession rules and audit working papers and other audit data.

\section{Improve liabilities of CPA under the framework of special general partnership.}

Special general partnership has raised the requirement for CPAs who has to be cautious in to practice their profession. It has also contributed to the independent certified public accountants auditing standards and the strict implementation of professional standards, greater protection of 
legitimate rights and interests of investors. However, as a new system, there are still many shortcomings that need to be refined and improved. In this respect, we believe that attempts in improving the relevant legal responsibilities should focus on the following aspects:

\subsection{Develop a scientific and rational evaluation system for responsibilities.}

Certified Public Accountants to be a reasonable division of responsibility for the type of attribution of responsibility type, it must be the responsibility of a scientific and rational evaluation system. The evaluation index system should be the primary responsibility for evaluation, which is a clearly defined responsibility of the CPA, which are the responsibility of the audited entity is the CPA's professional competence or problems caused by personal motives, are the responsibility of fraud or negligence and so on [7]. This requires a comprehensive evaluation index system to identify, evaluate or liability is difficult to be fair, reasonable and objective.

\subsection{Reasonable responsibility allocation criteria}

An audit is a strong systematic professional work, but also a holistic task that requires all aspects of staff complement each other, and is likely to lead to complete failure if problem exists in any part of the work flow. The rational allocation of responsibilities is difficult. To solve this problem, the first accounting firm to improve the internal quality control standards, and different criteria for each assignment weight, clear allocation of responsibilities for each part of personnel standards, and fixed in the form of Duty, thereby strengthening everyone's responsibility, clear accountability, help improve the quality of audit work, but also conducive to the interests of investors are not infringed.

\subsection{Develop compensation subjects and standards and implementation details}

Compensation definition of the subject should be more operational. In the implementation details should be made clear under what circumstances, investors suffered losses was only identified as an object can be admired, and asked to provide appropriate support material, rather than a personal statement alone makes compensation real reason is to protect the Information for investors based on the report. Payment standard should make a reasonable limit. For example according to the scale of investment, investment holding period, transaction records, trade credit and so on. Considering the object of each level of compensation payment standard. This needs to run more in line with the market.

\subsection{Strengthen the responsibility of the restraint mechanism.}

Responsibility on investors in order to ensure fairness, we should create favorable investor protection mechanisms. Improve the relevant legislation, qualified accountant or firm up a defense mode and intensity. Legal manner by the majority of investors jointly determined, a notary public shall safeguard the interests of investors stand point of view, the judge or other authority members of the suspected asylum CPA or accounting firm behavior, and should be punished or investigated for legal liability. Thus, to establish a fundamental responsibility of protecting the interests of investors restraint mechanism, certified public accountants and accounting firms to practice prudent to form a pressure.

\subsection{Improve the responsibility disclosure mechanism and incentive mechanism.}

Special general partnership and effective operation. Accounting firm to rely on the one hand, the internal unity and cooperation of all partners; on the other hand also needs an effective external supervision. Well developed internally and externally, it can only make this new mode of operation to be healthy and sustainable way to grow. External supervision can effectively measure the responsibility of regular or irregular disclosure mechanism and the corresponding incentive mechanism [8] .we have implemented regulation aimed at regulating the market operation, protect the legitimate rights and interests of investors, regulate market order. Responsibility for disclosure through the guide mechanism and incentive mechanism for Certified Public Accountants and accounting firms to strengthen the sense of responsibility to improve the operational capacity, prudent practice, correct conduct, to provide for investment decision-making authority of useful 
information.

\section{Summary}

The special general partnership brings fresh blood, provides vast development space to the industry of CPA. It also brings more challenges to the capital market. It becomes a hot topic of how to effectively protect investors' lawful rights and interests. This article holds that it is a key point of creating responsibility evaluation system and strengthening constraint mechanism. Obviously, as a new-born partnership, we are still on the way of exploring it. With the reform furthers, this partnership will be a high-effective operation model which will fundamentally promote the healthy and fast development of capital market and protect the investors' lawful rights and interests.

\section{Acknowledgements}

Zhenpeng $\mathrm{Ma}$ is the corresponding author. We appreciate helpful comments from Professor Bai Yunxia, Li wei, Zhong Ninghua, Yan Mengying, Yu Feng, Qiu Muqing, Wang Yanping at Tongji University, the conference participants at the 2014 Chinese Accounting society annual meeting in Beijing National accounting institute and the $1^{\text {st }}$ Chinese accounting and finance annual meeting in Xiamen University. All opinions and errors are the authors alone. We appreciate financial support by the National Nature Science Fund (Grant No.71472138; No.71402123; 71572073) and National Social Science Fund (Grant No.16BGL061).We are also appreciate thankful the Special Fund of Central University Basic Research Expense (Grant No.1200219243) and Philosophy and Social Science Fund in Colleges and Universities in Jiangsu Province (Grant No. 2017SJB0229).

\section{References}

[1] The Ministry of Finance of People’s Republic of China. (2009)Several Opinions on Fastening the Development of CPA Industry, Journal of Accounting Studies, 10, 2-4.

[2] Xiaohong Bai. (2007) Comprehension of Special General Partnership, Chinese Certified Public Accountants, 8, 4-6.

[3] Lingyun Zhao: (2009)Analysis of current Situation and Strategy of Special General Partnership in Accounting Firm, Communication of Finance and Accounting, 12, 78-80.

[4] Yingchun Song. (2007)Ideas on Internal Governance in Accounting Firm, Communication of Finance and Accounting, 6, 54-55.

[5]Shicheng Tian. (2007)The Perfection of Special General Partnership, Henan Social Science, 5, 34-37.

[6] Hodgkinson.R. (2007)The Development of Company Governance and Its influence on Accounting Firm, Chinese Certified Public Accountants, 2, 45-47.

[7] Limin.Zhang. (2006)Perfecting Company's Internal Governance to Effectively Avoid Auditing Risks-Enlightment of Internal Governance of Accounting Firm of Foreign Countries, Chinese Certified Public Accountants , 9, 68-69.

[8] Yanjun Qiao. (2008)Special General Partnership and the Strength of Accounting Firm, Chinese Certified Public Accountants, 4, 65-66. 